\title{
Transcatheter closure of a residual postmyocardial infarction ventricular septal defect with the Amplatzer septal occluder
}

\author{
E M Lee, D H Roberts, K P Walsh
}

\begin{abstract}
Acute ventricular septal rupture following myocardial infarction carries a high mortality. Early surgery improves survival but long term outcome depends on residual shunting and left ventricular function. Residual shunting is common despite apparently successful closure and may require reoperation. Transcatheter closure is an established method of treating selected congenital defects but clinical experience of transcatheter closure in postinfarction ventricular septal rupture is minimal. Transcatheter closure of a residual ventricular septal defect was successfully done using a new device, the Amplatzer septal occluder, in a 50 year old Indian man who had previously undergone emergency surgical repair for postinfarction acute ventricular septal rupture. The technique is described and its potential as a treatment in postinfarction ventricular septal rupture, its possible complications, and the important aspects of case selection and device design are discussed.

(Heart 1998;80:522-524)
\end{abstract}

Keywords: ventricular septal defect; transcatheter closure; Amplazter septal occluder

Acute ventricular septal rupture following myocardial infarction carries a high mortality. Without surgery, only $50 \%$ of patients survive the first week and fewer than $20 \%$ survive for one month. Hospital mortality following emergency repair ranges from $10 \%$ to $60 \%$ depending on the preoperative clinical characteristics of the patient population. Despite successful initial repair, ventricular septal defects (VSD) recur in $10-20 \%$ of patients because of patch dehiscence, development of a new VSD, or an overlooked second VSD. ${ }^{1}$ This residual defect may cause significant haemodynamic disturbance or haemolysis requiring reintervention. We report the successful transcatheter closure of a residual VSD using the Amplatzer septal occluder in a patient who had previously undergone emergency surgical repair for postinfarction acute ventricular septal rupture.

\section{Case report}

A 50 year old Indian man was admitted with a large anterior myocardial infarction. He received thrombolytic treatment with streptokinase, and remained stable until the third postinfarction day when he developed tachycardia, hypotension, oliguria, pulmonary oedema, and a new pansystolic murmur. Intravenous inotropes and intra-aortic balloon counterpulsation were started. Echocardiography showed anteroseptal akinesia and a mid-septal VSD. Coronary angiography showed a critical proximal left anterior descending artery stenosis. He underwent emergency coronary artery bypass grafting and VSD repair. Necrotic myocardium was excised and the $15 \times 10 \mathrm{~mm}$ defect patched with Dacron using Teflon buttressed sutures. Predischarge echocardiography showed a small residual VSD. Following multiple readmissions to his local hospital with heart failure, residual pansystolic murmur, persistent hypotension (90/50 mm Hg), and dyspnoea on minimal exertion, he was referred back for reinvestigation. Transoesophageal echocardiography (TOE) (fig 1) and cardiac catheterisation showed a $10 \mathrm{~mm}$ diameter VSD with a 1.8:1 left to right shunt, pulmonary hypertension (45/28 $\mathrm{mm} \mathrm{Hg}$ ), and raised pulmonary wedge pressures (mean $26 \mathrm{~mm} \mathrm{Hg}$ ). The inferior and posterior left ventricular walls contracted well but septum and apex were akinetic. Transcatheter closure of the recurrent VSD was done 10 months after his myocardial infarction. Under general anaesthesia, the right femoral artery and vein and right internal jugular vein were cannulated and a multiplane transoesophageal probe (Hewlett-Packard Omniplane, Andover, Massachusetts, USA) passed. Intravenous heparin and cephalosporin were administered. The VSD was crossed using a retrograde arterial approach with a $7 \mathrm{~F}$ El Gamal catheter (Cordis, Bracknell, UK) and Wholey wire (Intervention, UK). The El Gamal catheter was advanced into the left pulmonary artery over the Wholey wire, which was then exchanged for a 0.035 inch exchange length guidewire (Cordis). The end of this wire was then snared in the pulmonary artery with a $25 \mathrm{~mm}$ Amplatz goose-neck snare (Microvena; Vadnais, Minnesota, USA) and then extruded 

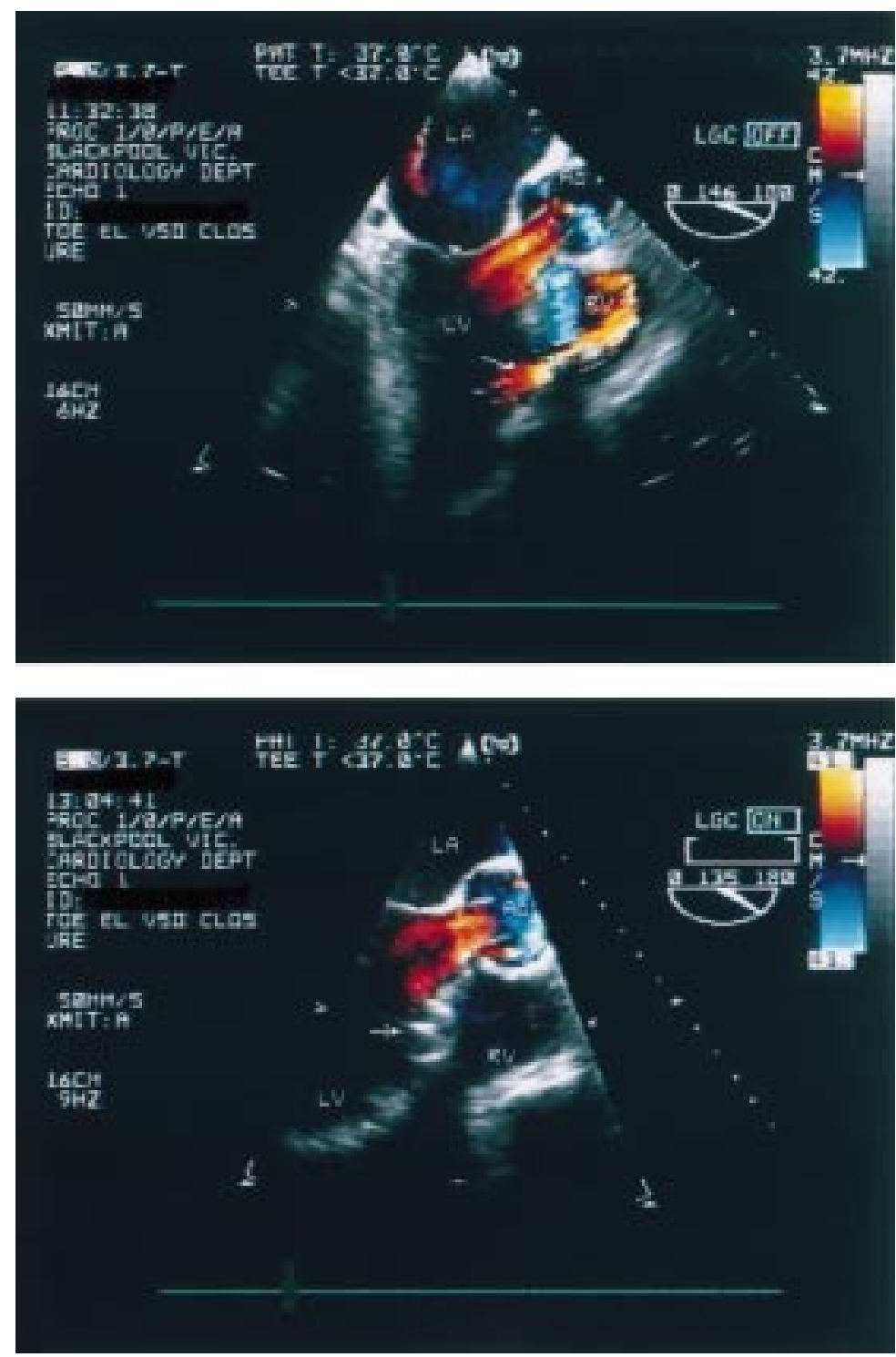

Figure 1 (Top) Preprocedure transoesophageal echocardiogram. Colour flow Doppler shows a significant left to right shunt across the VSD (arrow). (Bottom) Transoesophageal echocardiogram following deployment of the Amplatzer septal occluder (arrow) with obliteration of the left to right shunt. $L A$, left atrium; $L V$, left ventricle; $R V$, right ventricle, Ao, aorta.

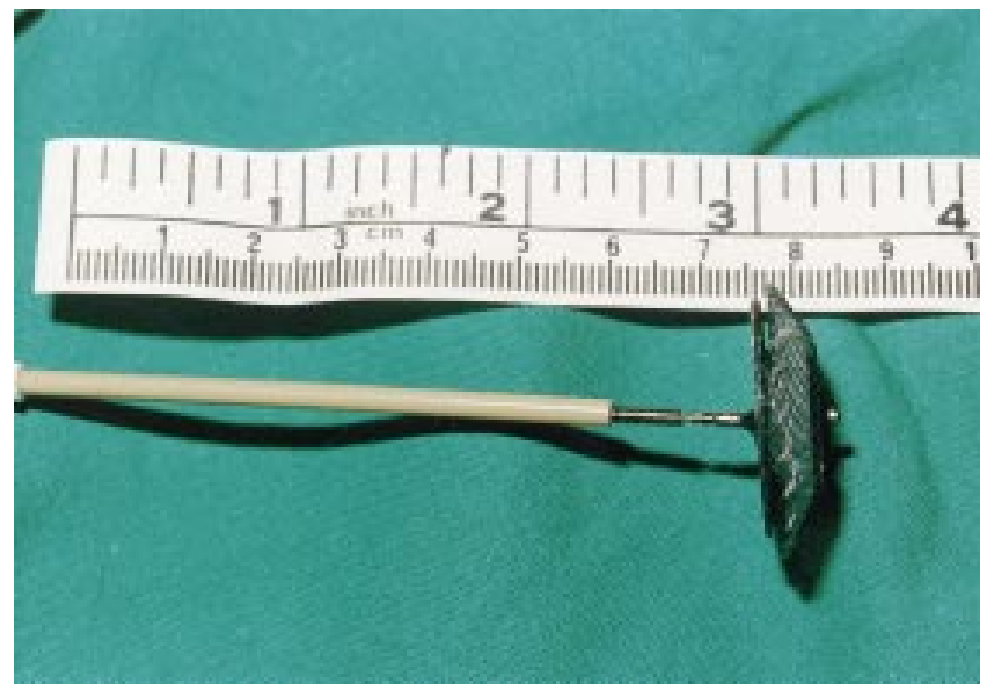

Figure 2 An Amplatzer septal occluder. via the right internal jugular vein, thereby creating an arteriovenous guidewire loop. A $7 \mathrm{~F}$ double lumen wedge balloon catheter (Kimal, UK) with a pre-calibrated balloon was passed over this wire into the left ventricle via the internal jugular sheath. The balloon was inflated with dilute contrast and the balloon volume that produced VSD occlusion on TOE and just pulled through the defect was noted. This gave a "stretched" diameter of $10 \mathrm{~mm}$. A $7 \mathrm{~F}$ long sheath was advanced from the jugular vein into the left ventricle. A $10 \mathrm{~mm}$ Amplatzer septal occluder (fig 2) was screwed onto the delivery cable, compressed into the loader, and introduced into the long sheath. The distal disc was extruded and pulled back onto the left ventricular side of the septum under TOE guidance. Once TOE confirmed septal alignment, the proximal (right ventricular) disc was deployed (fig 3). The device was then released by counterclockwise rotation of the delivery wire. TOE (fig 1) and left ventriculography showed only trivial left to right shunting through the device, while repeat oxygen saturations showed no detectable shunt. Transient complete heart block occurred during sheath removal but resolved spontaneously after a brief period of temporary transvenous pacing. Transthoracic echocardiography the following day showed a trivial residual shunt and the patient was discharged.

The patient felt immediate symptomatic improvement. At follow up seven weeks later he was well and his breathlessness was much improved. There were no clinical signs of heart failure and his pansystolic murmur was barely audible. Transthoracic echocardiography showed only trivial left to right shunting.

\section{Discussion}

Early surgery improves survival following acute postinfarction ventricular septal rupture ${ }^{1}$ but long term outcome depends on residual shunting and left ventricular function. Sutures may tear out easily from acutely infarcted myocardium to result in life threatening suture line rupture and patch dehiscence. Residual shunting is common despite apparently successful closure. In our patient, a significant residual shunt remained with preserved inferior and posterior left ventricular contractility.

Transcatheter devices for postinfarction VSD closure may provide short term haemodynamic stabilisation before urgent surgery, ${ }^{2}$ an interim measure to allow myocardial strengthening by scarring before definitive surgery, or a permanent alternative to primary or redo surgery. ${ }^{34}$ Clinical experience so far is limited. Early transcatheter closure has shown little survival benefit, but outcome was good in three cases of late transcatheter closure of postoperative residual VSD. ${ }^{3}$ Devices used to date include the Rashkind double umbrella ${ }^{4}$ and the Clamshell occluder. ${ }^{3}$ We used a new device, the Amplatzer septal occluder (fig 2), ${ }^{5}$ which consists of a self expanding double disc made of Nitinol wire mesh, containing three polyester patches. The two discs are linked by a short connecting waist corresponding to the size of the septal defect. It is self centring and retriev- 


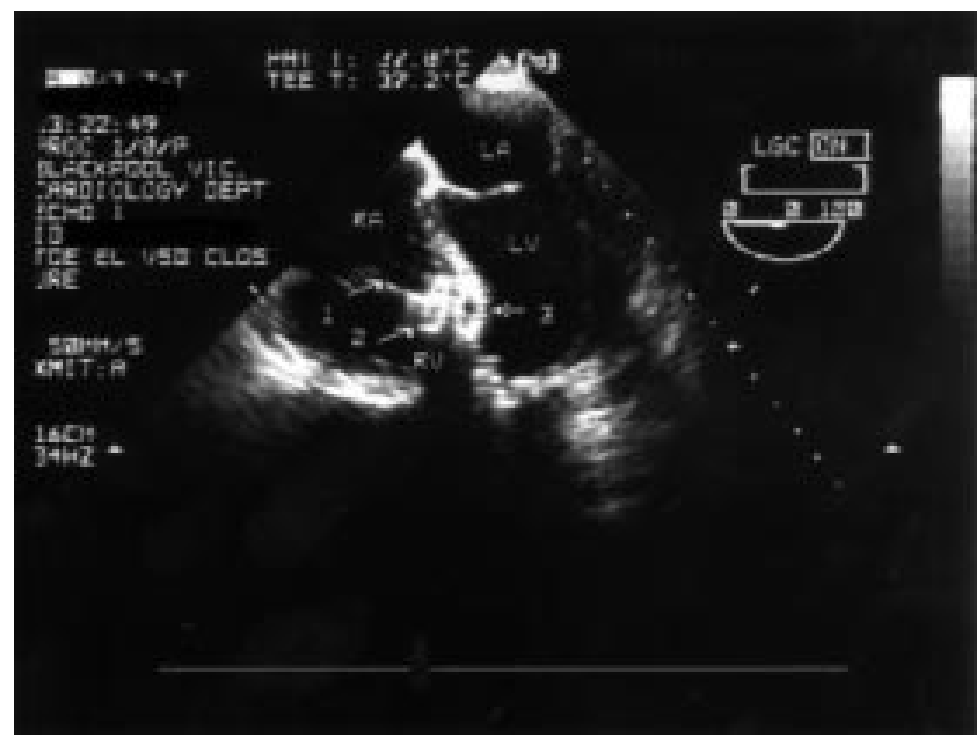

Figure 3 Transoesophageal echocardiogram showing the Amplatzer septal occluder positioned across the VSD before release from the delivery wire. $L A$, left atrium; LV, left ventricle; $R A$, right atrium; $R V$, right ventricle; arrow 1 , delivery wire; arrow 2 , proximal (right ventricular) disc; arrow 3, distal (left ventricular) disc.

able before release allowing several positioning attempts. Its low profile permits deployment through a $7 \mathrm{~F}$ introducer. As the device is a single construct, spontaneous disc separation does not occur. The waist is sized to fit the defect, closing it by defect stenting and secondary thrombosis. Defect fixation and occlusion depend less on firm disc apposition than other devices, which rely solely on counterclamp fixation and patch occlusion, and are therefore less affected by septal wall irregularities, attack angle, and degree of discseptal rim overlap.

Device migration has been the main complication of transcatheter closure. Its main causes are operator inexperience, inaccurate sizing, inaccurate deployment, inadequate rim for device fixation, and, in the case of the Sideris buttoned device, spontaneous disc separation. ${ }^{6}$ This results in inadequate defect closure, device embolism or encroachment on adjacent structures. Trapping of mitral or tricuspid chordae and encroachment upon the aortic valve $^{7}$ may lead to valvar regurgitation. Large defects and those too close to vital structures are unsuitable for transcatheter closure. The easy deployment procedure, retrievability, self centring defect stenting mechanism, and single unit construct of the Amplatzer septal occluder may reduce device migration. Its smaller, rounded discs decrease encroachment on adjacent structures and are less likely to inflict damage than devices with struts or sharp corners. ${ }^{8}$ Dysrhythmias such as complete heart block $^{7}$ may occur but are transient, while thromboembolism ${ }^{9}$ and prosthesis endocarditis are rare.

Multiplane TOE is a valuable adjunct to fluoroscopy in patient selection, device positioning, and shunt assessment. ${ }^{10}$ However, the balloon stretched diameter of the defect should be used to select device size ${ }^{5}$ as measurements by echocardiography may underestimate defect size.

Transcatheter closure is an established method of treating selected congenital defects. ${ }^{3}$ The clinical design of the Amplatzer septal occluder may improve outcome. We have demonstrated its potential as an alternative to late reoperation in recurrent postinfarction VSD following patch repair. More experience is needed to assess its value as a primary closure technique or bridge to surgery in acute ventricular septal rupture.

1 Caputo M, Wilde P, Angelini GD. Management of postinfarction ventricular septal d. 1995;54:562-66.

2 Hachida $M$, Nakano $\mathrm{H}$, Hirai $\mathrm{M}$, et al. Percutaneous transaortic closure of postinfarctional ventricular septal rupture. Ann Thorac Surg 1991;51:655-7.

3 Landzberg MJ, Lock JE. Interventional catheter procedures used in congenital heart disease. Cardiol Clin 1993;11:569-

4 Lock JE, Block PC, McKay RG, et al. Transcatheter closure of ventricular septal defects. Circulation 1988;78:361-8.

5 Sharafuddin MJA, Gu X, Titus JL, et al. Transvenous closure of secundum atrial septal defects. Preliminary results with a new self-expanding nitinol prosthesis in a swine model. Circulation 1997;95:2162-8.

6 Agarwal SK, Ghosh PK, Mittal PK. Failure of devices used for closure of atrial septal defects: mechanisms and for closure of atrial septal defects: mechanisms a

7 Sideris EB, Walsh KP, Haddad JL, et al. Occlusion of congenital ventricular septal defects by the buttoned device. Heart 1997;77:276-9.

8 Vogel M, Rigby ML, Shore D. Perforation of the right aortic valve cusp: complication of ventricular septal defect closure with a modified Rashkind umbrella. Pediatr Cardiol 1996;17:416-18.

9 Prewitt KC, Gaither NS, Farb A, et al. Transient ischemic attacks after long-term clamshell occuder implantation for closure of atrial septal defect. Am Heart f 1992;124:1394-6.

10 Van der Velde ME, Sanders SP, Keane JF, et al. Transoesophageal echocardiographic guidance of transrransoesophageal echocardiographic guidance of trans1994;23:1660-5. 